\title{
A produção de subjetividades no romance e na entrevista midiática: rastros do autobiográfico e da escrita feminista de Maria Valéria Rezende
}

The production of subjectivities in the novel and the media interview: traces of the autobiographical and feminist writing of Maria Valéria Rezende

\author{
Cândida de Oliveira \\ Tânia Regina Oliveira Ramos \\ Universidade Federal de Santa Catarina, Florianópolis, Santa Catarina, Brasil
}

Resumo: Este estudo investiga os discursos do biográfico na contemporaneidade sob a forma do romance e da entrevista midiática. Para tanto, retoma a obra de Philippe Lejeune sobre a noção de "pacto autobiográfico", procura estabelecer diálogos com estudos que demarcam novos modos de pensar a relação do biográfico com a subjetividade a partir do conceito de espaço biográfico, de Leonor Arfuch, e a crítica literária feminista. Com esse aporte teórico, visa analisar a produção de subjetividades na literatura brasileira contemporânea, focando a literatura de autoria feminina e tendo como corpus de análise Outros cantos, de Maria Valéria Rezende, publicado em 2016, e duas entrevistas concedidas pela escritora, veiculadas nos sites dos jornais $O$ Globo e El Pais. Constata a emergência de uma escrita de viés feminista, em que narrativas ficcionais e autobiográficas são tecidas com o apoio da memória.

Palavras-chave: Literatura; Espaço autobiográfico; Subjetividade; Crítica feminista; Maria Valeria Rezende

\begin{abstract}
This study investigates biographical discourses in contemporaneity in the form of novel and of the media interview. To the end, it resume the work of Philippe Lejeune about the notion of "autobiographical pact", seeks to establish dialogues with studies that demarcate new ways of to think the relationship of the biographical with subjectivity from the concept of biographical space, by Leonor Arfuch, and feminist literary criticism. With this theoretical contribution, it aims to analyze the production of subjectivities in contemporary Brazilian literature, focusing the literature of female authorship and having as corpus of analysis Outros Cantos, by Maria Valéria Rezende, published in 2016, and two interviews given by the writer, publishied on sites of the newspapers $O$ Globo and El Pais. On article notes the emergence of feminist bias writing, in which fictional and autobiographical narratives are wittren with the support of memory.
\end{abstract}

Keywords: Literature; Autobiographical space; Subjectivity; Feminist criticism; Maria Valéria Rezende 


\section{Da visibilidade das escritas e das vidas}

O movimento da subjetividade associado à proliferação e às transformações dos discursos representativos do biográfico no mundo contemporâneo, para além dos gêneros consagrados ao ato de escrever (gráphein) a vida (bios) de alguém (como biografias, autobiografias, confissões, memórias...), desperta cada vez mais o interesse de pesquisadoras e da academia em geral pela literatura íntima ou o que é denominado como escrita de si. Nossa leitura busca compreender esse movimento retomando, inicialmente, o clássico debate instaurado na década de 1970, na França, por Philippe Lejeune, um dos primeiros intelectuais franceses a tentar estabelecer as bases teóricas da autobiografia, a partir de três textos específicos: O pacto autobiográfico, de 1975, O pacto autobiográfico (bis), de 1986, e O pacto autobiográfico, 25 anos depois, de $2001^{1}$. Nossa intenção é, assim, fazer essa retomada no pacto inaugurado, reelaborado por ele nas suas autocríticas e revisões como suporte para a ressignificação que Leonor Arfuch dá ao privilegiar a entrevista na sua elaboração teórica e história sobre o espaço biográfico e os dilemas das subjetividades.

Depois, procuramos estabelecer um diálogo com estudos mais recentes que demarcam novos modos de pensar a relação do biográfico e da subjetividade, como os de Leonor Arfuch (2010) e os da crítica literária feminista, que se debruça mais especificamente sobre falas de mulheres e a importância de saber o que elas dizem. A partir deste aporte teórico, buscamos investigar a produção de subjetividades na literatura brasileira contemporânea, focando principalmente a literatura de autoria feminina representada aqui pela escritora Maria Valéria Rezende e sua proposta de além de se dar a ler, se dar a ver seja pelos depoimentos, pelas entrevistas, pelas fotos, pela inserção nas redes sociais, seja pela participação em festivais e feiras literárias como a Flip de Paraty e a recente Mulherio em João Pessoa. Assim como a autobiografia foi, durante muito tempo, desconsiderada pela historiografia, pela crítica literária e pelos estudos acadêmicos, a literatura de autoria feminina nem sequer ocupava um lugar no campo, sendo excluída ou negada nos espaços canônicos (MUZART, 2016 [1995]. Ouvir a voz e dar rosto às mulheres que escrevem é uma luta que busca se solidificar na década de 1970 quando transformações emergem, impulsionadas pelos movimentos feministas que ocorrem em vários lugares do mundo. No Brasil, com as formulações e estudos sobre o tema "Mulher e Literatura", na época, promoveram a

\footnotetext{
Esses textos estão compilados, juntamente com outros que retraçam a trajetória teórica do autor, na coletânea $O$ pacto autobiográfico: de Rousseau à Internet (LEJEUNE, 2008), utilizada como referência neste trabalho.
}

institucionalização acadêmica da crítica literária feminista (FUNCK, 2016 [1994]) e a criação da Editora Mulheres, idealizada e concretizada por Zahidé Lupinacci Muzart, fundamental para o questionamento dessa condição de subalternidade imposta aos escritos de mulheres. Assim, o atual contexto literário e cultural brasileiro é marcado pelo novo interesse em escritoras mulheres que então (re) aparecem em cena, como se busca evidenciar no ensaio "Talentos e formosuras: novas vozes, novos espaços" (RAMOS, 2010)

Procuramos analisar a produção de subjetividades na literatura de autoria feminina elegendo como corpus o romance Outros cantos (2016), de Maria Valéria Rezende, premiado com Casa de las Americas $2017^{2}$ e a importância de sua autora Maria Valéria Rezende. Por essa razão, além do livro, o corpus é constituído por duas entrevistas concedidas pela autora, veiculadas nos sites de dois veículos jornalísticos amplamente conhecidos: os jornais $O$ Globo (nacional) e El País (internacional). Desse modo, investigaremos a produção de subjetividades tanto na narrativa em questão quanto na entrevista midiática, entendida como uma das formas narrativas assumidas pelos discursos representativos do biográfico na contemporaneidade, conforme sinaliza Leonor Arfuch (2010).

\section{Questões iniciais da escrita autobiográfica: revendo Lejeune}

Na década de 1970, Lejeune procurou constituir um inventário e entender o funcionamento de textos autobiográficos na França, criando a noção de "pacto autobiográfico". ${ }^{3}$ Em 1975, o autor tentou estabelecer as bases teóricas para a legitimação do gênero, publicando o ensaio $O$ pacto autobiográfico, no qual propôs abordar a autobiografia a partir do ângulo da recepção, com intuito de esclarecer as problemáticas derivadas das clássicas discussões sobre as relações entre biografia e autobiografia, romance e autobiografia, que ele buscou então distinguir. ${ }^{4}$

Inicialmente, o autor definiu a autobiografia como uma "narrativa retrospectiva em prosa que uma pessoa

\footnotetext{
2 Trata-se do maior prêmio literário de Cuba. A escolha de Outros cantos foi motivada pela proximidade com o tema de pesquisa de doutorado, em andamento, de uma das autoras, sobre produções biográficas e autobiográficas de personagens da ditadura militar no Brasil, escritas por jornalistas brasileiros.

3 Trata-se do texto L'autobiographie en France, publicado em 1971, sem tradução para a língua portuguesa.

4 Motivado por essa leitura, Serge Doubrovsky escreve Fils, em 1977, e propõe o termo "autoficção" para caracterizar seu livro, dando assim uma resposta à tipologia apresentada por Lejeune, entendendo-a como restrita. Posteriormente, Lejeune repensa o pacto efetivando não apenas releituras e autocríticas de sua teoria, mas também de sua própria trajetória teórica, valendo-se inclusive da escrita autobiográfica.
} 
real faz de sua própria existência, quando focaliza sua história individual, em particular a história de sua personalidade" (LEJEUNE, 2008 [1975], p. 13). Nessa definição entram em jogo a forma da linguagem, o assunto tratado, a situação do autor e a posição do narrador. Para Lejeune, há certa flexibilidade nesses elementos, sendo isso o que permitiria à autobiografia estabelecer transição com outros gêneros da literatura íntima como memórias, biografia, romance pessoal ou autobiográfico, diário, correspondências, entre outros.

Partindo do modelo clássico da autobiografia, definido com base na obra Confissões, de Rousseau, escrita em 1782, Lejeune lembra que "[...] a identidade narrador-personagem principal, suposta pela autobiografia, é na maior parte das vezes marcada pelo emprego da primeira pessoa" (LEJEUNE, 2008 [1975], p. 16, grifos do autor). Isso é desdobrado então numa problemática sobre a identidade entre autor e narradorpersonagem, que Lejeune entende ser o critério definidor da autobiografia e de outros gêneros da literatura íntima, logo associado à questão do nome próprio. Segundo o autor, é a identidade do nome o que permitiria distinguir a autobiografia do romance autobiográfico, hipótese que se confirmaria pelo nome impresso na capa do livro. Assim, segundo Lejeune, a autoria é sustentada por uma convenção social, um compromisso de responsabilidade do autor baseado em uma existência real de uma pessoa. O autor é caracterizado como alguém que escreve, publica e assume uma série de textos diferentes, não se reduzindo a nenhum deles.

Nessa perspectiva, é possível afirmar que Maria Valéria Rezende assume-se como autora não apenas pela publicação de Outros cantos ${ }^{5}$. Além disso, no romance em questão, o primeiro nome da protagonista, Maria, remete diretamente ao primeiro nome da autora. No entanto, a identidade não se confirma, uma vez que a personagem é caracterizada na narrativa por um único nome. Essa breve semelhança do nome parece remeter à definição que Lejeune propõe para o romance autobiográfico, pois os textos que apresentam um personagem com nome fictício, mesmo que levem o leitor a pensar que a história vivida pelo personagem é a história do autor, "[...] não é uma autobiografia, já que esta pressupõe, em primeiro lugar, uma identidade assumida na enunciação, sendo a semelhança produzida pelo enunciado totalmente secundária.” (LEJEUNE, 2008 [1975], p. 25, grifos do autor).

O elemento que distingue a autobiografia do romance autobiográfico é, para Lejeune, a identidade entre

\footnotetext{
5 Desde 2001, a escritora lançou vários livros de ficção, como Vasto mundo, $O$ voo da guará vermelha, Modo de apanhar pássaros à mão $\mathrm{e}$ Quarenta Dias (premiado com o Jabuti 2015).
}

personagem e autor com o uso do nome próprio. Caso o nome do autor e o do personagem sejam diferentes, a possibilidade da autobiografia é excluída. Quando se confirma a identidade, fica excluída a possibilidade da ficção. Lejeune insiste na questão do nome próprio: "O que define a autobiografia para quem a lê é, antes de tudo, um contrato de identidade que é selado pelo nome próprio" (2008 [1975], p. 33). Mas porque tanta ênfase no nome próprio? Na ótica de Lejeune, há uma “[...] espécie de paixão pelo nome próprio, que ultrapassa a simples 'vaidade de autor', já que, através dela, a própria pessoa que justifica sua existência" (2008 [1975], p. 33, grifos do autor). Por isso, na fase inicial de seus estudos, ele entende que o tema principal da autobiografia é o nome próprio.

Voltando ao romance Outros cantos, permanecem questões sobre a identidade entre autora e narradorapersonagem. Maria não é um pseudônimo, não é diferente do nome da autora, mas também não é o nome completo. Essa relação não é prevista nos modelos iniciais de Lejeune, nem como exceção. Como caracterizar, então, a proposta de Outros cantos, em que o nome da narradorapersonagem principal remete, ainda que brevemente, ao nome da autora?

Há que nos lembrarmos nessa perspectiva, de Roland Barthes por Roland Barthes, publicado em 1975, onde o teórico francês reflete sobre os nomes próprios, lançando uma questão que parece soar como uma resposta às afirmações de Lejeune. Afinal "como se pode ter uma relação amorosa com os nomes próprios?" (BARTHES, 1977 [1975], p. 57). Na mesma obra, o próprio Barthes responde: "Não é apenas uma linguística dos nomes próprios que se faz necessária; é também uma erótica: o nome, como a voz, como o odor, seria o termo de um langor: desejo e morte: 'o último suspiro que resta das coisas' [...]” (1977 [1975], p. 58). Barthes, em sua autobiografia, propõe um jogo narrativo entre autor, personagem e narrador, usando diferentes termos - "eu", "ele", "RB" - para caracterizar textualmente quem fala e de quem fala, ao longo de todo livro. Ele explica:

Quando finjo escrever sobre o que outrora escrevi, acontece, do mesmo modo, um movimento de abolição, não de verdade. (...). Não digo: "Vou descrever-me", mas: "Escrevo um texto e o chamo de R.B.". Dispenso a imitação (a descrição) e me confio à nominação (BARTHES, 1977 [1975], p. 64).

Esse jogo caracteriza o que, em reflexões posteriores, Lejeune confirmará sobre a escrita autobiográfica: no enunciado, o sujeito é uma construção discursiva. Em O pacto autobiográfico (bis), analisando a autobiografia de Barthes como um exemplo de antipacto, Lejeune faz 
uma releitura autocrítica de seu posicionamento: "Dizer a verdade sobre si, se constituir um sujeito pleno, trata-se de um imaginário" (LEJEUNE, 2008 [1986], p. 65-66). Ele confirma assim a existência de uma "ideologia autobiográfica", na qual, porém, não deixa de acreditar quando afirma: "[...] por mais que a autobiografia seja impossível, isso não a impede de existir." (LEJEUNE, 2008 [1986], p. 66). É nesse movimento de autocrítica, todavia, que Lejeune constata o aspecto normativo do pacto, a apresentação categórica que fez do problema da identidade enquanto aspecto central na definição da autobiografia. O autor reconhece sua tendência a cristalizar um eixo único para a autobiografia, e pondera sobre a existência de muitas posições intermediárias.

$\mathrm{Na}$ leitura de Outros cantos sobre esse aspecto, o nome da personagem, Maria, parece remeter, com certas nuances, à autora. Em nosso entendimento, tratase aí também de um jogo que permite caracterizar o romance como autobiográfico. Mas a identificação dos rastros autobiográficos não se restringe ao nome próprio, visto que, como explica Pierre Bourdieu (2006 [1986], p. 189-190):

Tentar compreender uma vida como uma série única e por si suficiente de acontecimentos sucessivos, sem outro vínculo que não a associação a um "sujeito" cuja constância certamente não é senão aquela de um nome próprio, é quase tão absurdo quanto tentar explicar a razão de um trajeto no metrô sem levar em conta a estrutura da rede, isto é, a matriz de relações objetivas entre as diferentes estações. [...] $\mathrm{O}$ que equivale a dizer que não podemos compreender uma trajetória (...) sem que tenhamos previamente construído os estados sucessivos do campo no qual ela se desenrolou e, logo, o conjunto das relações objetivas que uniram o agente considerado [...] ao conjunto dos outros agentes envolvidos no mesmo campo e confrontados com o mesmo espaço dos possíveis.

Tanto na autobiografia quanto no romance autobiográfico, o narrador-personagem é sempre uma construção que inclui a invenção. Esse aspecto ficará mais evidente nos últimos estudos de Lejeune, quando o autor estuda outras formas autobiográficas e narrativas "ordinárias". Isso se torna perceptível inclusive no modo como ele descreve sua trajetória teórica, mostrando um estilo cada vez mais metafórico e subjetivo. Por fim, acaba por aceitar que a subjetividade é sempre aberta, múltipla, é sempre um "je" (eu/jogo), como em Un "jê" de pistes (LEJEUNE, 2015). Em outro momento de autocrítica e revisão teórica, Lejeune (2008 [2005], p. 74) afirma: "Hoje, sei que transformar sua vida em narrativa é simplesmente viver. Somos homensnarrativas."

\section{Do pacto autobiográfico ao espaço biográfico}

Em um de seus ensaios mais recente, intitulado $O$ pacto autobiográfico, 25 anos depois, escrito em 2001 e publicado em 2005, Lejeune reflete sobre os propósitos claramente normativos presentes desde seu primeiro texto sobre o tema, dando ênfase à noção de "pacto autobiográfico". Em sua visão, a autobiografia a la Rousseau seria uma das muitas combinações possíveis, mas o essencial permanece sendo, independente da modalidade narrativa, o pacto: "[...] o objeto do discurso de verdade que se prometeu cumprir" (LEJEUNE, 2008 [2005], p. 81). Desse modo, o autor reconhece que o pacto autobiográfico por ele concebido é, sobretudo, um "pacto de verdade" que pode ser entendido também como um contrato de leitura prometendo um compromisso com a verdade, e por organizar linhas de força que vão orientar a leitura e reação ao texto.

É possível afirmar que Lejeune encontrou inúmeras dificuldades de estabelecer os limites da prosa e da ficção, da transparência e da verossimilhança. Essas dificuldades existiram porque, segundo Lejeune (2008 [1986], p. 61) "[...] o paradoxo da autobiografia literária, seu jogo duplo essencial, é pretender ser ao mesmo tempo um discurso verídico e uma obra de arte." Diante disso, o teórico considerou mais adequado designar um centro do sistema autobiográfico que seria a tensão entre transparência referencial e a preocupação estética.

As reflexões de Lejeune, fundamentais para compreensão do gênero autobiográfico, como já dissemos, estimularam outros estudos, como os da teórica argentina Leonor Arfuch. Em $O$ espaço biográfico: dilemas da subjetividade contemporânea, Arfuch (2010) investiga os gêneros discursivos auto e biográficos e a ênfase dada à singularidade no contexto da cultura contemporânea. A autora chama a atenção para a multiplicidade e a proliferação das formas narrativas que esses discursos assumem no espaço midiático. Segundo ela, existe uma obsessão por deixar impressões, rastros e inscrições por meio da escrita, algo que, até pouco tempo, parecia ser atendida pelas biografias, autobiografias, confissões, memórias, diários íntimos e correspondências. Hoje, salienta a autora, essas formas desdobram-se em entrevistas, conversas, perfis, retratos, anedotários, testemunhos, histórias de vida, relatos de autoajuda, talk show, reality show etc., denotando um fenômeno que é significativamente mais amplo:

[...] a notável expansão do biográfico e seu deslizamento crescente para os âmbitos da intimidade fazem pensar num fenômeno que excede a simples proliferação de formas dissimilares, os usos funcionais ou a busca de estratégias de mercado, para expressar uma tonalidade particular de subjetividade contemporânea (ARFUCH, 2010, p. 16). 
Assim, na coexistência dos diferentes gêneros discursivos e suas formas narrativas, estaria em jogo um "algo a mais", "uma tonalidade particular" de subjetividade contemporânea, não importando mais tanto assim as diferenças mas as relações possíveis entre um e outro gênero.

Desenvolvendo um denso arcabouço teórico, Leonor Arfuch (2010) mostra como o campo da subjetividade foi se desenvolvendo, especialmente a partir da década de 1980, com o cenário dos debates sobre o fim da modernidade que sinalizavam a crise dos grandes relatos legitimadores, a perda de certezas e fundamentos, o descentramento do sujeito, e, com isso, a valorização dos pequenos e microrrelatos, favorecendo o aparecimento "[...] da pluralidade de vozes, da hibridização, da mistura irreverente de cânones, retóricas, paradigmas e estilos." (ARFUCH, 2010, p. 17). A autora destaca a configuração de um novo espaço público fundamentado não apenas pelo interesse comum e a visibilidade democrática, mas também pela incorporação da vida privada, pela "invasão" da privacidade e atração que as novas formas de expressão despertam nos leitores e expectadores. A partir disso, Arfuch ressignifica o conceito de espaço biográfico, como

[...] uma espacialização [...] onde confluíam num dado momento formas dissimilares, suscetíveis de serem consideradas numa interdiscursividade sintomática, por si só significantes, mas sem renunciar a uma temporalização, a uma busca de heranças e genealogias, a postular relações de presença e ausência. (ARFUCH, 2010, p. 22, grifos da autora).

A noção de espaço biográfico, tomada de empréstimo de Lejeune, foi o ponto de partida de Arfuch para estudar a inovação midiática implicada nos discursos do auto e biográfico, sem renunciar às formas clássicas. Com base neste amarramento conceitual, a autora propõe então uma articulação das formas de subjetivação não determinadas por dotes intrínsecos ou por uma hierarquia de narrativas, mas considerando aqueles que contribuíram para a afirmação de uma nova privacidade dentro desse espaço biográfico.

$\mathrm{Na}$ interatividade das formas, Arfuch observa a importância de um gênero predominante na comunicação midiática: a entrevista, recorte central e fundamental para nossa leitura. Em sua perspectiva, a entrevista condensa os "tons" que marcam nossa época: "[...] a compulsão de realidade, a autenticidade, o 'ao vivo', a presença" (ARFUCH, 2010, p. 23, grifos da autora). A entrevista é, conforme a autora, a mais antiga e emblemática maneira de dialogar, raciocinar, trazer à tona, encontrar uma verdade. A forma mais próxima da voz, e, por isso, um dos principais "acentos" do eu, desse "retorno do sujeito" que pretende fazer ouvir sua "própria" palavra.

A entrevista é uma forma ubíqua, capaz de apresentar o leque completo de posições de sujeito da sociedade, capaz de recorrer todas as modulações do vivencial, revelando assim novos contornos de subjetividade. A entrevista midiática, de modo específico, ofereceria a possibilidade de abarcar dois polos arquetípicos da experiência: o das vidas "célebres", que são emblemáticas e se tornam objeto de identificação, e o das vidas "comuns", que oferecem uma imediata possibilidade de autorreconhecimento. Como nas entrevistas com escritores, duplamente emblemáticas porque englobam num mesmo texto tanto o mito da "vida e obra" quanto quem cria relatos diversamente autobiográficos.

Seguimos na direção apontada por Arfuch, que supõe o biográfico "[...] como um espaço intermediário, às vezes como mediação entre público e privado; outras como indecidibilidade" (ARFUCH, 2010, p. 28), e a entrevista midiática como espaço de devir biográfico. Trata-se de pensar a qualidade (inter)subjetiva do gênero, no sentido de uma virtualidade biográfica, como um "[...] dom peculiar de induzir, mesmo direcionada para outros objetivos, a exposição da interioridade, da afetividade, da experiência" (ARFUCH, 2010, p. 31). Assim, a escrita autobiográfica não serve somente para alimentar "o mito do eu" numa lógica narcisista ou de voyeurismo, mas opera, prioritariamente, "[...] como ordem narrativa e orientação ética nessa modelização de hábitos, costumes, sentimentos e práticas, que é constitutiva da ordem social" (ARFUCH, 2010, p. 31-32).

É nessa perspectiva que o romance e a entrevista midiática também podem ser compreendidos como formas narrativas representativas dos discursos (auto) biográficos. Tomando emprestadas as palavras de Arfuch, compreendemos os materiais em análise neste trabalho como espaços emblemáticos capazes de mostrar que "[...] a narração de uma vida, longe de vir a 'representar' algo já existente, impõe sua forma (e seu sentido) à vida mesma" (ARFUCH, 2010, p. 33, grifos da autora). Reforçamos o entendimento de que a escritura se apresenta como textualidade, onde a crítica e a teoria intervêm possibilitando diferentes leituras.

\section{Por que saber o que elas falam: entre nós as vozes}

Além das perspectivas teóricas já abordadas, a crítica feminista também constitui o aporte de teorias que sustenta esse trabalho sobre escrita de si, subjetividade e literatura de autoria feminina. Nesse sentido, são destacados conceitos e elementos históricos que me parecem fundamentais para compreender o que estamos denominando "escrita feminista". 
A partir da segunda fase da crítica literária feminista, conhecida como "ginocrítica", expressão cunhada por Elaine Showalter na década de 1980, a existência de uma estética feminina reconhece, conforme explica Susana B. Funck (2016 [1994]), uma consciência literária especificamente feminina. Na terceira fase, ainda com base no estudo de Showalter, Susana Funck observa que a crítica literária feminista passou a reconhecer a produção literária feminina, propondo uma revisão dos conceitos básicos do estudo literário. A crítica norte-americana e as tradições inglesa e francesa contribuíram para o crescente interesse pela teoria, promovendo-se a quebra das fronteiras culturais e enfatizando a análise da construção do gênero e da sexualidade no discurso literário. De acordo com Susana Funck (2016 [1994]), a crítica literária passou então da questão da mulher às questões de gênero. Na década de 1990, a categoria gênero já era bastante utilizada nos estudos acadêmicos. No campo da literatura, essa noção contribui para inaugurar uma fase caracterizada por um crescente interesse de investigação do modo pelo qual a atividade literária é marcada por diferenças de gênero.

Tomando como referências as narrativas autobiográficas de sete mulheres feministas contemporâneas ao período da ditadura militar no Brasil, eixo central do romance Outros cantos de Maria Valéria Rezende, a historiadora brasileira Margareth Rago (2013) apresenta, em A aventura de contar-se, como as "escritas de si" enquanto práticas e modos de ação política e cultural podem dar relevo a " [...] experiências intensas, miúdas e constantes de construção de outros modos de pensar, agir e existir em prol da autonomia feminina." (RAGO, 2013, p. 28). A autora trata de experiências de invenção subjetiva e de inserção política dessas mulheres, levando em conta os efeitos produzidos pela irrupção do feminismo na cultura brasileira, nos últimos 40 anos. Ressaltamos que, para a autora, os feminismos são como linguagens que se referem não apenas aos movimentos autodenominados feministas, mas também “ “....] a práticas sociais, culturais, políticas e linguísticas, que atuam no sentido de libertar as mulheres de uma cultura misógina e da imposição de um modo de ser ditado pela lógica masculina nos marcos da heterossexualidade compulsória." (2013, p. 28).

Em seu estudo, Margareth Rago constatou que essas mulheres feministas, ao relatar/ narrar suas vidas, “[...] desfazem as linhas de continuidade histórica, questionam identidades construídas e constituem-se relacionalmente como sujeitos múltiplos" (2013, p. 32), demonstrando preocupação com a reinvenção de si, da relação com o outro numa perspectiva ética. Além disso, "[...] romperam, cada qual a seu modo, com os padrões tradicionais de conduta impostos às mulheres, com os valores e códigos morais estabelecidos, questionando o regime de verdades da época [...]" (RAGO, 2013, p. 34).
Com base nas elaborações de Foucault sobre a "escrita de si", a autora procurou "[...] explorar os espaços que se abrem a partir da linguagem e da escrita como prática de relação renovada de si para consigo e também para com o outro" (RAGO, 2013, p. 30). Nessa perspectiva, diferentemente da biografia e de outras técnicas, a escrita de si corresponde a uma forma de autonomia e afirmação das subjetividades. As narrativas autobiográficas são consideradas "práticas de liberdade" que constituem uma estética específica de existência feminista. Rago (2013, p. 55) assinala: "[...] a 'escrita de si' constitui uma chave analítica pertinente para pensar as práticas de resistência nas narrativas dessas feministas que se recusam a ser governadas." Nessa mesma chave interpretativa, segundo a autora, discursos autobiográficos podem ser entendidos também como "práticas de autoconstituição".

Dessa forma, de acordo com Margareth Rago (2013), as escritas de si podem evidenciar a luta contra a normatividade imposta sobre as mulheres, configurandose como práticas discursivas efetivamente feministas. Elas revelam as lutas contra as formas contemporâneas de controle biopolítico dos corpos e impulsionam as buscas de afirmação de novos modos de expressão subjetiva, política e social. Quando instaladas em novos territórios, essas narrativas expõem vivências de modo crítico aos valores morais e às verdades instituídas, mostrando as possibilidades de um trabalho voltado tanto a si quanto para a luta em defesa da dignidade, da justiça social e da ética. Nessa abordagem, os relatos autobiográficos são possibilidades de reconstrução do passado, de avaliação de experiências vividas e modos de se dar sentido ao presente. São, sobretudo, formas de constituir a própria subjetividade, que permitem explorar a constituição discursiva de sujeitos feministas, bem como valorizar, ressignificar ou silenciar suas experiências.

É a partir dessa perspectiva feminista, razão de aqui a justificarmos, que procuraremos olhar Outros cantos, de Maria Valéria Rezende (2016), bem como às entrevistas concedidas pela autora e veiculadas nos sites dos jornais O Globo, em 05 de janeiro de 2016 (FREITAS, 2016), e El país em 24 de fevereiro de 2017 (MORAES, 2017).

\section{Memória e escrita autobiográfica}

Para ouvir Maria Valéria Rezende escolhemos duas entrevistas entre as muitas que a escritora tem dado à mídia televisiva e impressa. A razão de nossa escolha se deve não só pelas respostas que ela dá, mas as perguntas que a ela foram feitas, o que possibilitaria uma reflexão mais apurada de nossas hipóteses da importância da voz da escritora. A entrevista publicada em $O$ Globo, assinada pelo jornalista Guilherme Freitas, tem como foco o anúncio do lançamento de Outros cantos, destacando 
no título que o romance é inspirado na atuação da autora durante a ditadura. Maria Valéria Rezende é apresentada como escritora e freira, que sempre trabalhou como educadora popular - primeiro em SP, depois no Nordeste -, seguindo as ideias de Paulo Freire. Outros elementos aparecem ainda no texto introdutório, compondo o perfil de escritora que o jornalista the atribui: "Nascida numa família de literatos (o poeta Vicente de Carvalho, integrante da ABL, era seu tio-avô), Maria Valéria, de 73 anos, só estreou na literatura em 2005, com o romance 'O voo da guará vermelha"' (FREITAS, 2016, online, grifo nosso) .

A jornalista Camila Moraes é quem assina a outra entrevista que, publicada em El País, repercute o premio internacional Casa das Américas e a participação da autora na Flip 2017. Diferentemente da outra entrevista, o posicionamento crítico e feminista da escritora ganha destaque desde o título: "Maria Valéria Rezende: 'As pessoas pensam que freiras são bobinhas. Como podem escrever literatura?'” (MORAES, 2017, online). $\mathrm{Na}$ descrição de seu perfil, outras expressões que a singularizam: "escritora talentosa da literatura brasileira contemporânea", "75 anos", "freira missionária" e "vive fora do eixo Rio-São Paulo". Como consta na abertura da entrevista, "Maria Valéria Rezende [...] não é o que se espera de um 'novo nome das letras nacionais' e nem uma 'freira/veterana/escritora juvenil', como ela mesma conta que já a descreveram por aí. [...] Maria Valéria Rezende não espera encaixar no que costumam dizer sobre ela" (MORAES, 2017, online). Elementos que reforçam a ruptura com o perfil médio (elitista) de escritores brasileiros ${ }^{6}$.

A partir das duas entrevistas, outros dados da vida da escritora ganham visibilidade, permitindo que esses elementos sejam relacionados às narrativas e personagens dos romances que escreve. Assim, de sua história, sabese que Maria Valéria Rezende nasceu em Santos (SP) e que, na década de 1960, integrou a Juventude Estudantil Católica e entrou para a Congregação de Nossa Senhora - Cônegas de Santo Agostinho. Por meio da entrevista, tomamos conhecimento de sua atuação durante a ditadura militar e viagem para outros países. Em uma das entrevistas, destaca-se que Maria Valéria Rezende "[...] ajudou a esconder opositores após o golpe de 1964 e chegou a sair do país, em 1972 [...]. Passou por Itália, França, Argélia, EUA e México antes de voltar ao Brasil.." (REZENDE, 2016, online). Na outra, ganham vez as lembranças de sua passagem por Cuba "[...] a voz rouca de Maria Valéria ao telefone sobe alguns tons em emoção e volume quando relembra os anos vividos em Cuba" (MORAES, 2017, online):

\footnotetext{
6 Pesquisa coordenada por Regina Dalcastagnè (2012) mostra que a maioria dos escritores brasileiros são homens, brancos, com idade média de 50 anos, ensino superior completo e vivendo no eixo Rio São Paulo.
}

Meus laços com a América Latina têm origem na ditadura militar brasileira [...]. A gente reconstruiu, ao longo dos anos 60 e 70, uma rede de educação popular. [...] Em Cuba, também fizeram uma cruzada de alfabetização no começo da Revolução Cubana.

$[\ldots]$

Fiquei hospedada um tempo em uma casa oficial do Governo cubano ao lado da casa onde fica o Gabriel García Márquez. [...]. Eu ficava lá, junto, batendo papo, contando histórias do interior do Nordeste e coisas assim. O Fidel era uma pessoa interessantíssima também. Tinha uma memória brutal. E um interesse em conversar comigo, porque eu vinha da zona canavieira e ele tinha uma curiosidade de saber como era a vida dos trabalhadores da cana.

$[\ldots]$

Era interessante, porque não era escritora, nem nada. Eu era uma formiguinha. Mas uma formiguinha que tinha a sorte de estar em lugares interessantes. (REZENDE apud MORAES, 2017, online).

Não se trata de mero acaso, são os mesmos lugares pelos quais passou Maria, a narradora-personagem de Outros Cantos. O romance de Maria Valéria Rezende não é um livro de memória, nem uma autobiografia em sentido tradicional, clássico. Ao explicar como foi reviver as memórias da ditadura durante a escrita do romance, claramente autobiográfico em certos aspectos, Maria Valéria Rezende fornece pistas sobre o que dela própria pode ser relacionado à protagonista Maria:

\begin{abstract}
Autobiografias se passam por verdadeiras, mas no fundo são ficção. Então preferi dar a forma de um romance e ficar livre para reinventar tudo. A protagonista não tem nada da minha personalidade, não sou uma sonhadora, e as histórias que ela conta são inventadas. Mas o percurso dela é emprestado do meu. E a figura que aparece ao longo do romance com várias formas, um homem que a protagonista nunca sabe se é a mesma pessoa, tem a ver com uma experiência forte que vivi durante a ditadura. (REZENDE apud FREITAS, 2016, online, grifo nosso).
\end{abstract}

Neste fragmento, parece que as autocríticas de Lejeune são sintetizadas. Autobiografia e romance, ficção: tudo é reinvenção. O que pode variar é o grau de liberdade que o escritor tem para construir o seu (eu) personagem. Assim, aparecem as conexões possíveis de Outros Cantos com dados autobiográficos narrados pela escritora:

Escondi muita gente e ajudei muita gente a sair do país. As pessoas se apresentavam com um nome, mas sabíamos que era falso, e bastava raspar as sobrancelhas para que ficassem irreconhecíveis. Eram pessoas sobre quem eu não sabia nada, mas que colocavam as vidas nas minhas mãos. E eu colocava minha vida nas mãos 
delas [...]. Não existe relação mais íntima do que essa, quando duas pessoas que não se conhecem confiam suas vidas uma à outra e depois nunca mais se veem. (REZENDE apud FREITAS, 2016, online).

A experiência de Maria Valéria Rezende durante a ditadura serve assim de matéria para compor a subjetividade da personagem Maria como mulher militante de esquerda, na luta contra ditadura, sonhadora, educadora, crítica, por meio de termos chave como "exílio", "lutas", "esperanças", e inúmeros fragmentos no decorrer da narrativa, como nas seguintes passagens:

Por mais que buscasse, não encontrava outro caminho digno e honesto para os companheiros, conhecidos ou desconhecidos, com quem me tinha comprometido. Devia desenrolar-me sozinha, incomunicável pelo tempo que fosse necessário, para não despertar suspeitas, até criar as condições para a vinda dos outros.

$[\ldots]$

O caminho que, queríamos democrático, seria muito mais longo e diferente, nosso papel, mergulhar "no seio da massa", tornar-nos como "peixes dentro d'água", nas margens, nas fábricas, no campo, nas palafitas, nas serras, desaparecer como o "fermento em massa" [...].

Éramos muitos, decididos a assumir esse caminho, mas onde estariam os outros? Vivos? Desaparecidos, desanimados, apanhados pelos olhos perscrutadores da ditadura, torturados, resistindo ou não? Naqueles anos, para nós, a invisibilidade e a incomunicabilidade eram condições essenciais para o êxito (REZENDE, 2016, p. 105-106).

[...] percebia quão longo seria o caminho, mas eu queria, sim, ficar ali, cumprindo o papel que me deram eles de lhes contar histórias, ou o que me tinham dado os companheiros, de mudar a História, sob a máscara da professora que o governo mandou para ensinar gente grande a ler [...] (RESENDE, 2016, p. 144).

As memórias de Maria Valéria tecem assim outras memórias, de Maria e outras personagens do sertão que ganham voz e lugar nas histórias contadas em Outros cantos, tornando coletivas suas lembranças individuais, em um movimento que é também o da escrita autobiográfica (LACERDA, 2000), iluminando cenários não expostos pelos grandes refletores da história oficial.

A partir das entrevistas, apresentam-se os elementos biográficos que constroem o perfil da escritora, uma mulher que sempre se dedicou à educação popular, primeiro em SP e depois no Nordeste. A partir de 1972, Maria Valéria Rezende instala-se em Caraibeiras (PE), povoado isolado do sertão nordestino possivelmente retratado em Outros cantos sob o nome Olho d'Água. Depois, vai para o interior da Paraíba e em 1988, segue para João Pessoa, onde vive atualmente. Em uma das entrevistas, instigada pelo repórter a falar de suas memórias, Rezende (apud FREITAS, 2016, online) expõe sua lida com educação popular, algo que, para ela não se resume à alfabetização, mas compreende "[...] um processo complexo de ajudar as pessoas a refletir sobre o mundo a partir de suas próprias experiências." A autora acrescenta o intuito desse trabalho: "[...] queríamos ajudá-las a combater a visão fatalista de que quem nasce pobre vai morrer pobre", enfatizando o engajamento social e político envolvido. Ela via esse trabalho como uma "missão de desaparecer em meio ao povo" para atuar "como o fermento na massa" (REZENDE apud FREITAS, 2016, online, grifo nosso).

$\mathrm{Na}$ outra entrevista, Rezende expõe de que maneira os acontecimentos que viveu estão presentes em sua literatura, apresentando ao mesmo tempo sua visão sobre a relação - inextricável - entre vida e obra:

Não é que inspirem no sentido literal. Eu respirei o mundo inteiro, e isso entrou pelos meus cinco sentidos. Há uma variedade de lembranças, sensações, impressões... e é com isso que eu construo a minha literatura, sem dúvida nenhuma. Porque a minha cabeça nasceu vazia e tudo o que está lá dentro é porque entrou. Não fiz estudos de teoria literária, oficina de escrita criativa, nada disso. Então, o que escrevo só pode vir do que vi, ouvi, senti, cheirei, andei... Minha matéria prima certamente é isso e o que eu li toda a minha vida [...] (REZENDE apud MORAES, 2017, online).

Tanto no romance quanto na entrevista, são visíveis as relações de identificação entre a autora e a personagem para além da questão do nome e dos lugares por onde passaram. O percurso de ambas envolve, sobretudo, a atuação na educação de base no período da ditadura militar, que consistiu em uma forma de luta contra o regime, conforme enfatiza Rezende (apud FREITAS, 2016, online): "Muitos da nossa geração optaram pela luta armada ou pela militância cultural, outros seguiram o caminho da educação. Fomos milhares." A escritora ressalta que o seu livro retrata as pessoas cuja atuação tinha como condição a invisibilidade, e que continuam invisíveis, de certa forma, excluídos da história.

\section{Concluindo: outros pactos e as desterritoralizações subjetivas}

Além de dar visibilidade às pessoas que lutaram por um país mais justo por meio da educação popular, 
em Outros cantos, Maria Valéria Rezende joga luz sobre outros brasileiros que também são empurrados à margem da sociedade e história, focando o povo nordestino, expressando aquilo que viu e ouviu no sertão pernambucano e paraibano. Como enfatiza a autora em uma das entrevistas: "Todos os meus livros falam dos excluídos, porque só posso falar do que conheço" (REZENDE apud FREITAS, 2016, online).

Assim é que, em Outros cantos (2017), a autora aborda o mundo nordestino com riqueza lírica, misturando realidade e ficção, por meio de sua personagem que descreve o cenário sertanejo ao rememorar os tempos de outrora, como quando diz "custava-me caminhar pela areia solta daquela rua branca, como tinha me custado avançar pelas dunas do Saara [...]. O mesmo peso dos pés afundados na areia, a mesa confusão da vista encandeada pela luz brutal do sol sem o filtro da umidade nem da poeira" (REZENDE, 2017, p. 19) e ainda: "Trabalhava-se ali tanto quanto nunca pensei que se pudesse trabalhar." (REZENDE, 2017, p. 19); Em uma semana estava pronta a urdidura para transformar o fio bruto nas redes que me haviam embalado a infância e cuja doçura em nada denunciava o esforço sobre-humano e a dor que custavam." (REZENDE, 2017, p. 20); "Fui compreendendo. Ali, naquela beira de mundo, os únicos bens indispensáveis que só dinheiro comprava eram a água e o tear." (REZENDE, 2017, p. 33); “Aquele fim de mundo [...] tinha dono, o Dono, do morro que continha a milagrosa mina d'água perene, dono mesmo, 'de papel passado', disseram, dono da vida e da morte naquele território [...]" (p. 33); "Era preciso a labuta de uma família inteira, a vida inteira, só para pagar a ração mínima de líquido durante os longos meses de estio" (REZENDE, 2017, p. 33).

As transformações desse cenário surgem, em tom metafórico, na fala da personagem ao olhar pela janela do ônibus e ver "[...] junto a cada casa uma cisterna, [...] espalhadas ao longo deste trajeto antes de escurecer, novinhas, brancas, na forma de um peito materno [...]" (REZENDE, 2017, p. 15), ou então “[...] uma casa sertaneja isolada à beira da estrada, amplamente iluminada, luz elétrica em abundância", cheia de coisas no seu interior, "[...] muito mais coisas do que gente: sofás e poltronas forrados de plástico, imitando o mau gosto exibido pela televisão a despejar sua luz azulada e sons estridentes em alto volume [...] competindo com o ronco do ônibus velho [...]" (REZENDE, 2017, p. 21-22). Um algo nostálgico aparece na fala da personagem: "O sertão não é mais sertão e ainda não virou mar. Fecho os olhos e minha memória recupera e estiliza a beleza despojada daquele meu outro sertão" (REZENDE, 2017, p.22). "Apesar das aparências, nem tudo mudou tanto assim neste sertão" (REZENDE, 2017, p.45).
Os rastros de uma subjetividade nômade, errante, vivendo constantes desterritorializações subjetivas (RAGO, 2013) aparecem na narrativa, ancorada no relato em primeira pessoa, nas lembranças do passado sertanejo, evocadas por imagens, paisagens, cores e odores. Numa rica narrativa lírica e metafórica, as memórias encontram outras desfiadas dos amuletos guardados na "caixinha de patuás posta em sossego lá no fundo do baú" (REZENDE, 2016, p. 124). As rememorações vão construindo a personagem ao mesmo tempo em que a situam, no tempo da memória e no espaço em que ocorrem as histórias centrais da narrativa: "Eu fazia trinta anos no dia em que me meti pela primeira vez nesta aridez [...]. Vejo-me outra vez jovem ainda [...], naquele povoado cujo nome explicava a razão de sua existência, tão longe de tudo: Olho d'Água, como tantos outros mínimos oásis espalhados pela vastidão de terras secas" (REZENDE, 2016, p. 10).

As histórias sobre a primeira longa viagem ao sertão, suas primeiras experiências naquele lugar "tão longe de tudo", de onde não se costumava chegar, só ir embora, misturam-se a outras de outros lugares, de olhares promissores, vistos de relances, de amores impossíveis, seu "vaqueiro encantado", desdobram-se em histórias de sertanejos relembradas pela protagonista, e narrativas tecidas sobre outros andares por lugares distantes, e contadas por Maria àquela gente que mais do que aprender a ensinavam, gerando um potencial transformador e de invenção de novos espaços, pessoas, subjetivos e coletivos. Um trabalho de diferença vai se desenvolvendo na escrita, pelo estranhamento com o outro, com o lugar da mulher sertaneja, desenrolando-se em processos de identificação:

Às mulheres cabia a estranha dança para mover os enormes teares [...], os pés saltando de um para o outro dos quatro pedais que levantavam alternadamente os liços, os braços a lançar as navetas e a puxar o fio, estendo faixas de cor, a fazer surgir o xadrez das redes que eu tão bem conhecia [...], braços tão rápidos que pareciam ser muito mais de dois, transfigurando aquelas sertanejas em deusas indianas. (REZENDE, 2016, p. 20).

Era das mulheres também a tarefa infindável de buscar água potável na única fonte a escorrer, preguiçosa, em oásis com coqueiral [...], assim como a obrigação de controlar o movimento do burro a mover a nora [...]. O canto sob as algarobas era sinal de que já estavam os potes cheios, as cabras amarradas [...], o fogo aceso sob os telheiros entre as casas e os currais, moído o milho e consumido o cuscuz da madrugada, o feijão a ferver nos caldeirões de barro enegrecido [...]. Aquelas tarefas também eu tinha de aprender a cumprir. (REZENDE, 2016, p. 21, grifo nosso). 
Das histórias sobre as relações de amizade e solidariedade, de ajuda e aprendizado mútuos, das experiências de Maria junto a outras mulheres - Fátima, Fatuma, Lupita, dona Zefa do cajueiro, Alzira, D. Amélia, Maria do Socorro e tantas outras - emerge uma escrita de veia feminista, contribuindo para a desconstrução dos modos tradicionais de produção da subjetividade associada às mulheres:

Lembro-me, no meu primeiro encontro com aquele povo, em torno das banheiras fumegantes: assim que respondi mais uma vez "Maria, meu nome é Maria", ouvi "Eu sou Fátima". Havia uma única mulher a remexer uma caldeira de tinta, entre os homens mudos. Socorreu-me, com solidária coragem falou comigo, explicou-me cada coisa que eu via, pegou-me pela mão e me levou a ocupar seu posto enquanto ia olhar seu fogo, seu feijão, seus meninos, abriu um espaço para mim entre aquela gente que não me havia chamado, não precisava de mim. Um lugar fora de lugar, como o dela, no qual seríamos duas a receber no rosto o vapor ardente subindo da tina, a tingir o fio como um homem $[\ldots]$.

Encontrei ofício e família por aquele canto escondido. Podia ficar, preenchida de estranha euforia e subidamente livre de uma espécie de cegueira frente ao desconhecido, comecei a ver cada um, cada coisa, cada movimento na unidade e seu sentido. Pelas mãos de Fátima cheguei ali de verdade (REZENDE, 2016, p. 24).

No romance Outros cantos e nas entrevistas de Maria Valéria Rezende, somos levadas a considerar que o enlace entre ficção e elementos (auto)biográficos (seja pelo viés de Lejeune seja pela leitura de Leonor Arfuch) indicam os rastros de uma escrita feminista, que subverte "[...] os sistemas existentes que reprimem e negam a diferença" (FUNCK, 2016, p. 148), especialmente ao dar protagonismo a outros cantos e outras vidas culturalmente silenciadas e não representadas na literatura hegemônica. A voz do outro emerge em uma narrativa autobiográfica que concretiza, ao mesmo tempo, um efetivo trabalho de memória da voz que se faz ouvir seja pelo texto seja pela entrevista. A escritura autobiográfica apresenta-se assim como um exercício de alteridade, uma práxis de resistência, confirmando o que afirma Nelly Richard (2002 , p. 136-137): “[...] em toda cultura há entrelinhas rebeldes, por onde filtrar e disseminar os significados antipatriarcais".

\section{Referências}

ARFUCH, Leonor. O espaço biográfico: dilemas da subjetividade contemporânea. Tradução de Paloma Vidal. Rio de Janeiro: EdUERJ, 2010.
BARTHES, Roland. (1975). Roland Barthes por Roland Barthes. Tradução de Leyla Perrone-Moisés. São Paulo: Cultrix, 1977.

BOURDIEU, Pierre. (1986). A ilusão biográfica. In: AMADO, Janaína; FERREIRA, Marieta de Moraes (Org.). Usos e abusos da história oral. 8. ed. Rio de Janeiro: Editora FGV, 2006. p. 183-191.

DALCASTAGNÈ, Regina. Literatura brasileira contemporânea: um território contestado. Rio de Janeiro: Editora da UERJ; Vinhedo: Horizonte, 2012.

FREITAS, Guilherme. Maria Valéria Rezende lança romance inspirado em sua atuação contra ditadura. Entrevista concedida por Maria Valéria Rezende ao jornal $O$ Globo. 05 de janeiro de 2016. Disponível em: <https://oglobo.globo.com/cultura/ livros/maria-valeria-rezende-lanca-romance-inspirado-emsua-atuacao-contra-ditadura-3-18407009>. Acesso em: 11 set. 2017.

FUNCK, Susana Bronéo. (1994). Da questão da mulher à questão do gênero. In: FUNCK, Susana Bronéo. Crítica literária feminista: uma trajetória. Florianópolis: Insular, 2016. p. 145-153.

LACERDA, Lilian Maria de. Lendo vidas: a memória como escritura autobiográfica. In: MIGNOT, Ana Chrystina; BASTOS, Maria Helena Camara; CUNHA, Maria Teresa Santos (Org.). Refúgios do eu: educação, história e escrita autobiográfica. Florianópolis: Mulheres, 2000. p. 81-107.

LEJEUNE, Philippe. (1975). O pacto autobiográfico. In: LEJEUNE, Philippe. O pacto autobiográfico: de Rousseau à Internet. Tradução de Jovita Maria Gerheim Noronha, Maria Inês Coimbra Guedes. Belo Horizonte: Editora UFMG, 2008. p. 15-47.

LEJEUNE, Philippe. (1986). O pacto autobiográfico (bis). In: LEJEUNE, Philippe. O pacto autobiográfico: de Rousseau à Internet. Tradução de Jovita Maria Gerheim Noronha, Maria Inês Coimbra Guedes. Belo Horizonte: Editora UFMG, 2008. p. 48-69.

LEJEUNE, Philippe. (2005). O pacto autobiográfico, 25 anos depois. In: LEJEUNE, Philippe. O pacto autobiográfico: de Rousseau à Internet. Tradução de Jovita Maria Gerheim Noronha, Maria Inês Coimbra Guedes. Belo Horizonte: Editora UFMG, 2008. p. 70-85.

LEJEUNE, Philippe. Um "jê" de pistes. In: LEJEUNE, Philippe. Écrire sa vie: du pacte au patrimoine autobiographique. Paris: Mauconduit, 2015. p.11-25. (Neste trabalho, utilizamos a tradução de Claudia Renata Duarte, cedida em aula para esta finalidade).

MORAES, Camila. Maria Valéria Rezende: "As pessoas pensam que freiras são bobinhas. Como podem escrever literatura?". Entrevista concedida por Maria Valeria Rezende ao jornal El País. 24 fev. 2017. Disponível em: <https://brasil.elpais.com/ brasil/2017/02/20/cultura/1487625634_391058.html>. Acesso em: 11 set. 2017.

MUZART, Zahidé Lupinacci. A questão do cânone. In: RODRIGUES, Carla; BORGES, Luciana; RAMOS Tânia Regina Oliveira (Org.). Problemas de gênero. Rio de Janeiro: Funarte, 2016. p.305-314. 
RAGO, Margareth. A aventura de contar-se: feminismos, escrita de si e invenções da subjetividade. Campinas: Editora da Unicamp, 2013.

RAMOS, Tânia Regina Oliveira. Talentos e formosuras: novas vozes, novos espaços. In: DASCASTAGNÈ, Regina; LEAL, Virginia Maria Vasconcelos. Deslocamentos de gênero na narrativa brasileira contemporânea. São Paulo: Horizonte, 2010. p. 32-40.

REZENDE, Maria Valéria. Outros cantos. Rio de Janeiro: Alfaguara, 2016.
RICHARD, Nelly. A escrita tem sexo? In: RICHARD, Nelly. Intervenções críticas: arte, cultura, gênero e política. Tradução de Romulo Monte Alto. Belo Horizonte: Editora UFMG, 2002. p.127-141.

Recebido: $11 / 11 / 2017$

Aprovado: 10/04/2018

Contato:

Cândida de Oliveira <candida.oliveira07@gmail.com>

Tânia Regina Oliveira Ramos < taniareginaoliveiraramos@gmail.com> 